\title{
MODEL PEMBELAJARAN KIMIA KARBON BERBASIS GAME
}

\author{
Adriana Sari Aryani ${ }^{1}$ dan Aya Hartina ${ }^{2}$ \\ Fakultas MIPA, Program Studi Ilmu Komputer, Universitas Pakuan \\ Email:19adriana.aryani@gmail.com, ${ }^{2}$ ayahartina065112403@gmail.com
}

\begin{abstract}
Abstrak
Dalam kimia karbon terdapat banyak jenis ikatan kimia karbon dengan gugus fungsi yang berbeda-beda. Untuk dapat memahami mengenai hal tersebut tentu tidaklah cukup hanya dengan membaca buku saja, siswa harus lebih banyak berlatih untuk meningkatkan pemahamannya. Pendekatan multimedia dapat digunakan sebagai alternative dalam membuat media pembelajaran interaktif sebagai contoh yaitu membuat model pembelajaran interaktif untuk salah satu cabang ilmu kimia yaitu mengenai Kimia Karbon dengan judul "Model Pembelajaran Kimia Karbon Berbasis Game". Aplikasi ini dibuat menggunakan software Adobe Flash CS 6 dengan bahasa pemrograman ActionScript 3.0.

Metode yang digunakan pada penelitian ini adalah metode pengembangan multimedia dan design grafis yang terdiri dari enam tahapan, yaitu concept, design, material collecting, assembly, testing dan distribution. Setelah melakukan uji coba pada respondent siswa maka di raih hasil sebagai berikut : Effect :87,5\%, Control : 100\%, Efficiency : 100\%, Helpfulness : 80\%, Learnability : 90\%. Sedangkan pada respondent ahli di raih hasil sebagi berikut : Effect :92,5\%, Control : 100\%, Efficiency : 100\%, Helpfulness : 80\%, Learnability : 90\%. Model Pembelajaran Kimia Karbon ini di harapkan dapat di kembangkan menjadi sebuah game edukasi berbasis android, dengan menambahkan materi mengenai jenis reaksi yang ada pada senyawa karbon.
\end{abstract}

Kata kunci: pembelajaran kimia karbon, multimedia kimia, pembelajaran berbasis game

\begin{abstract}
In carbon chemistry there are many types of carbon chemical bonds with different functional groups. To be able to understand about it is certainly not enough just to read books alone, students should be more practice to improve understanding. Multimedia approach can be used as an alternative in making interactive learning media as an example that is making interactive learning model for one branch of chemistry that is about Carbon Chemistry with title "Learning Model of Carbon-Based Chemistry Game". This application is created using Adobe Flash CS 6 software with ActionScript 3.0 programming language.

The method used in this research is the method of multimedia development and graphic design consisting of six stages, namely concept, design, collecting material, assembly, testing and distribution. After doing the test on the respondent students then the results obtained as follows: Effect: 87.5\%, Control: 100\%, Efficiency: 100\%, Helpfulness: 80\%, Learnability: 90\%. While the respondent expert in the results obtained as follows: Effect: 92.5\%, Control: 100\%, Efficiency: 100\%, Helpfulness: 80\%, Learnability: 90\%. Carbon Chemistry Learning Model is expected to be developed into an android-based educational game, by adding material about the types of reactions that exist in carbon compounds.
\end{abstract}

Keywords:Carbon Chemistry Learning,chemical multimedia, game-based learning 


\section{PENDAHULUAN}

Senyawa organik atau lebih dikenal dengan Kimia Karbon merupakan salah satu cabang ilmu kimia yang di pelajari siswa tingkat Sekolah Menengah Atas (SMA). Dalam kimia karbon terdapat banyak jenis ikatan kimia karbon dengan gugus fungsi yang berbeda-beda. Untuk dapat memahami mengenai hal tersebut tentu tidaklah cukup hanya dengan membaca buku saja, siswa harus lebih banyak berlatih untuk meningkatkan pemahamannya. Penyediaan media pembelajaran interaktif dapat membantu siswa untuk berlatih mengerjakan soal-soal yang berhubungan dengan kimia karbon dimana saja dan kapan saja meskipun tanpa di dampingi seorang guru.

Pendekatan multimedia dapat digunakan sebagai alternative dalam membuat media pembelajaran interaktif. Dengan pengembangan yang sama yaitu pengembangan multimedia maka dilakukanlah penelitian untuk membuat model pembelajaran interaktif untuk salah satu cabang ilmu kimia yaitu mengenai Kimia Karbon dengan judul "Model Pembelajaran Kimia Karbon Berbasis Game". Model pembelajaran interaktif ini akan disajikan berupa permainan yang diharapkan dapat membantu siswa dalam mengingat, memahami konsep ikatan kimia karbon.

Tujuan penelitian ini adalah merancang dan menyajikan sebuah model pembelajaran interaktif mengenai Kimia Karbon berbasis Game berupa permainan sederhana yang menarik dan mudah dimengerti. Aplikasi ini dibuat menggunakan software Adobe Flash CS 6 dengan bahasa pemrograman ActionScript 3.0.

\section{METODE PENELITIAN}

Metode yang digunakan pada penelitian ini adalah metode pengembangan multimedia dan design grafis yang terdiri dari enam tahapan, yaitu concept, design, material collecting, assembly, testing dan distribution. Tahapan pengembangan multimedia ditunjukkan pada Gambar 1.

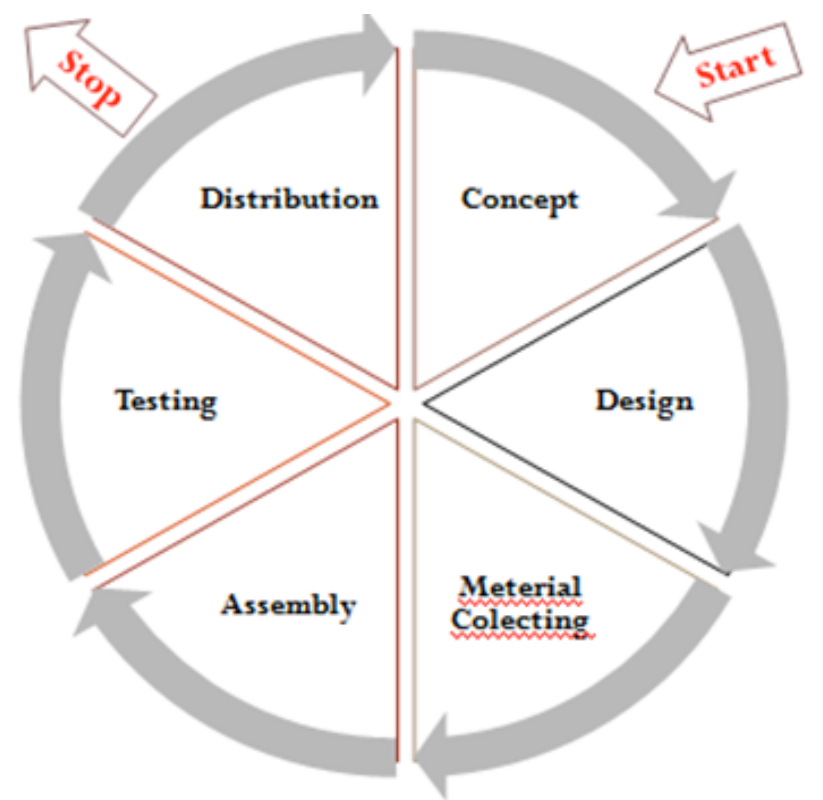

Gambar 1. Tahapan pengembangan multimedia 
Alat-alat yang digunakan dalam penelitian ini terdiri dari perangkat keras (hardware) dan perangkat lunak (software):

1. Spesifikasi Hardware
a) Processor Intel Core i3
b) RAM 2 GB
c) Printer Canon iP2770

2. Spesifikasi Software
a. Adobe Flash CS6
b. Adobe Photoshop CS6
c. Microsoft Word 2013
d. Microsoft Office Visio 2013

\section{PERANCANGAN}

Tahap design (perancangan) adalah tahap membuat spesifikasi mengenai arsitektur program, gaya, tampilan dan kebutuhan material/bahan untuk program. Tahapan design yang dilakukan adalah: Desain struktur navigasi, merupakan perancangan model navigasi dasar aplikasi, dapat dilihat pada gambar 2 .

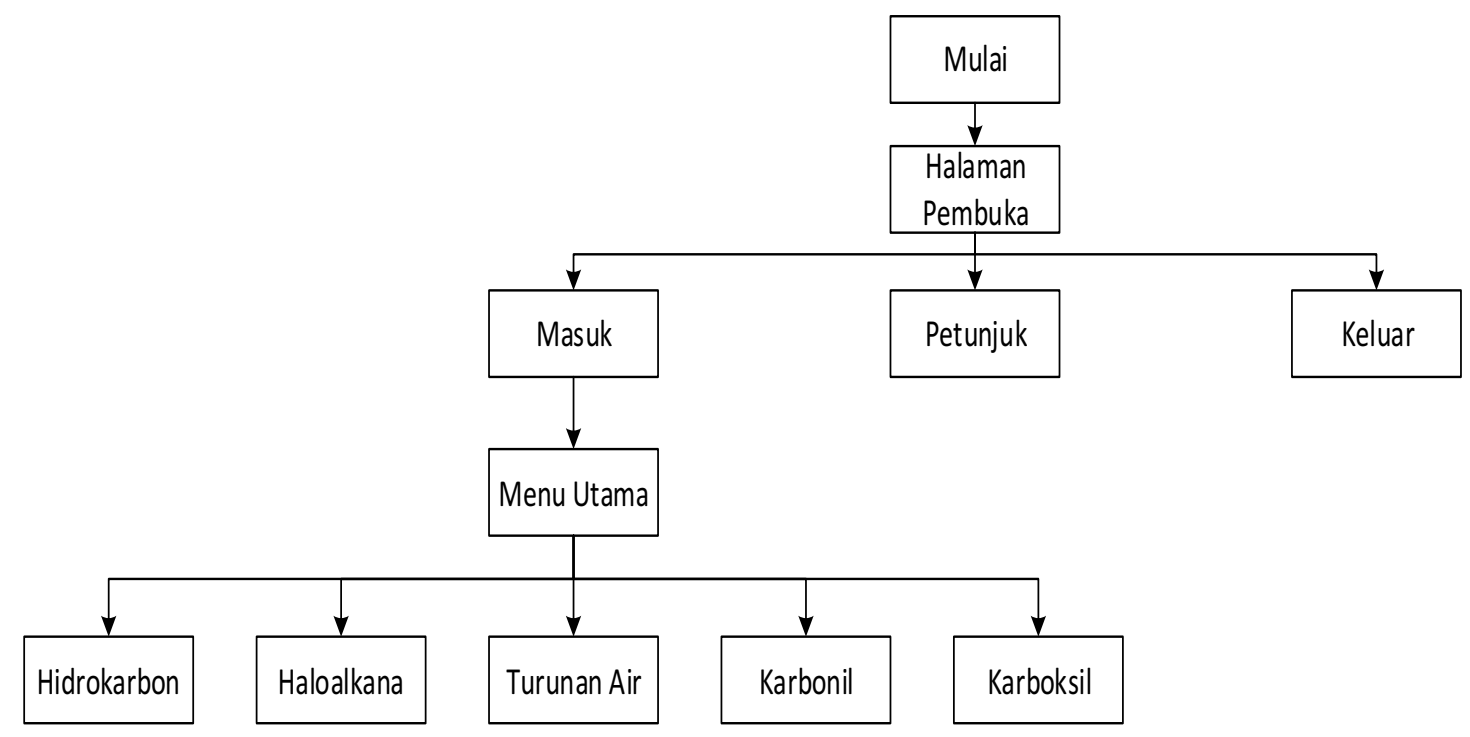

Gambar 2. Desain Struktur Sistem

Desain screen merupakan perancangan tampilan (interface).

$>$ Desain Halaman Pembuka

Pada halaman ini terdapat tiga button navigasi yaitu Masuk dan Keluar yang masingmasing memiliki fungsi. Button Masuk akan mengalihkan pengguna menuju halaman Menu Utama dan button keluar berfungsi untuk mengakhiri aplikasi atau juga membatalkan penggunaan aplikasi. 


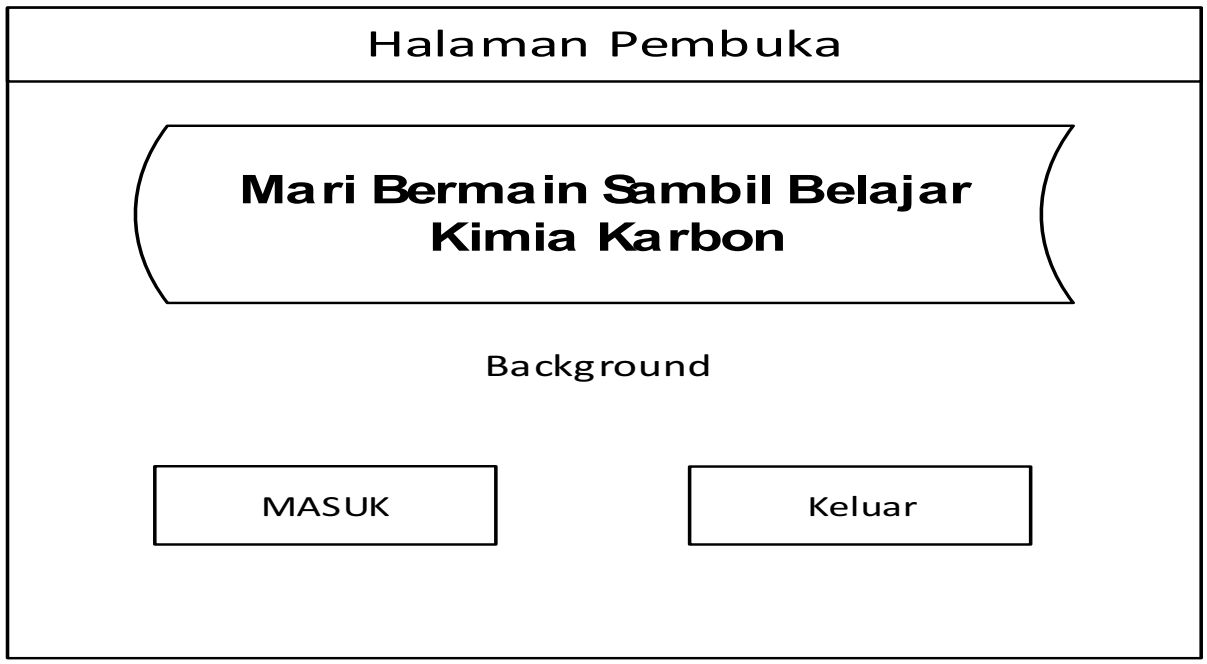

Gambar 3. Desain Layar Pembuka

Desain Menu Utama

Halaman Utama memiliki empat button navigasi yaitu button Mari Main yang berfungsi untuk mengalihkan pengguna menuju halaman permainan, button Tentang Kimia Karbon akan mengalihkan pengguna menuju halaman materi mengenai kimia karbon yang akan membahas mengenai dasar-dasar tatanama dan gugus fungsi yang ada pada kimia karbon, button Petunjuk Permainan akan mengalihkan pengguna menuju halaman petunjuk permainan yang akan memberikan perintah atau cara-cara melakukan permainan kimia karbon dan button kembali akan membawa pengguna kembali menuju halaman pembuka. Pada halaman ini teknik multimedia yang di gunakan adalah motion tween.

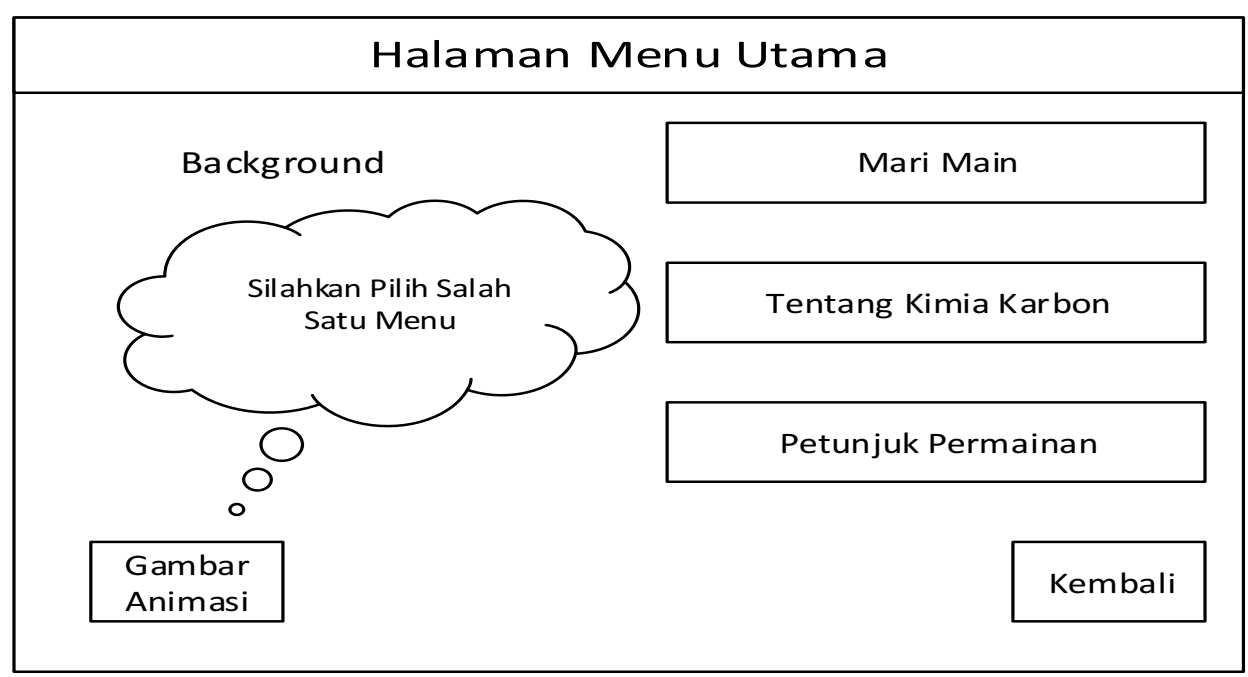

Gambar 4. Desain Menu Utama

Desain Halaman Menu Permainan

Jika pengguna memilih button mari main pada saat di menu utama maka pengguna akan masuk ke halaman menu permainan yang didalamnya terdapat enam button yang dapat dipilih. Setiap button memiliki nomor yang jika di pilih maka akan memasuki halaman permainan kimia karbon. 


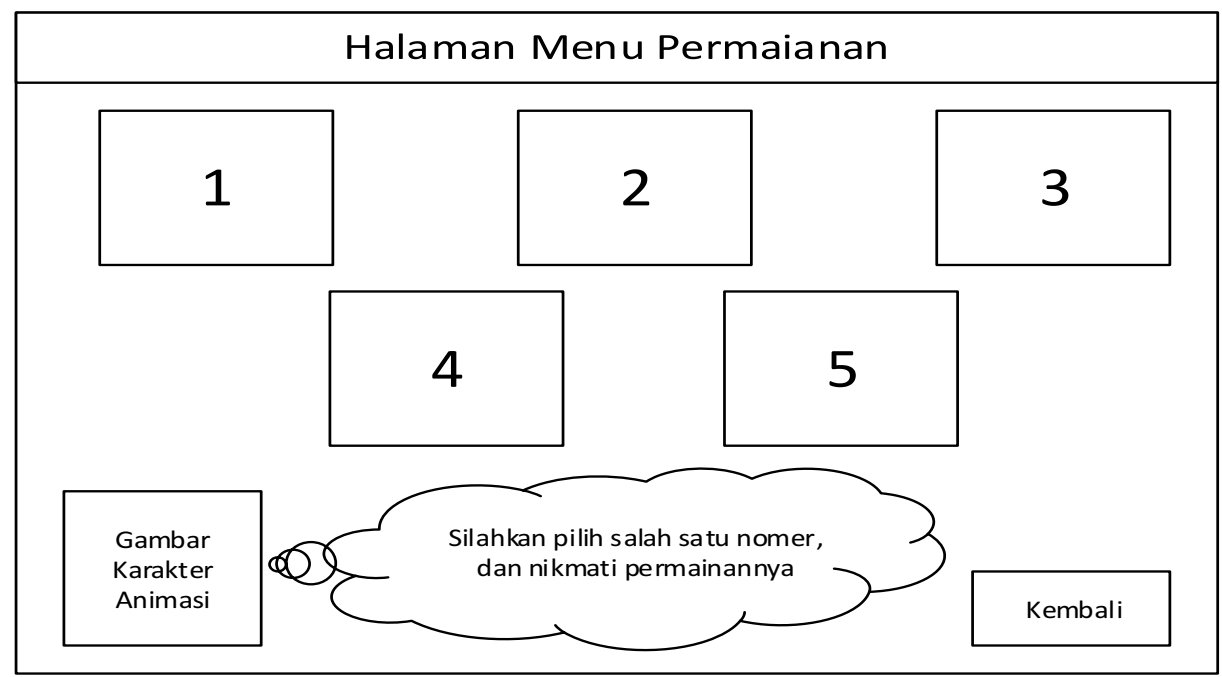

Gambar 5. Desain Menu Permainan

\section{HASIL DAN PEMBAHASAN}

Halaman menu pembuka adalah halaman awal untuk memulai penggunaan aplikasi, terdapat dua button navigasi yaitu masuk dan keluar. Jika memilih button masuk maka akan beralih menuju menu utama sedangkan button keluar berfungsi mengakhiri penggunaan aplikasi.

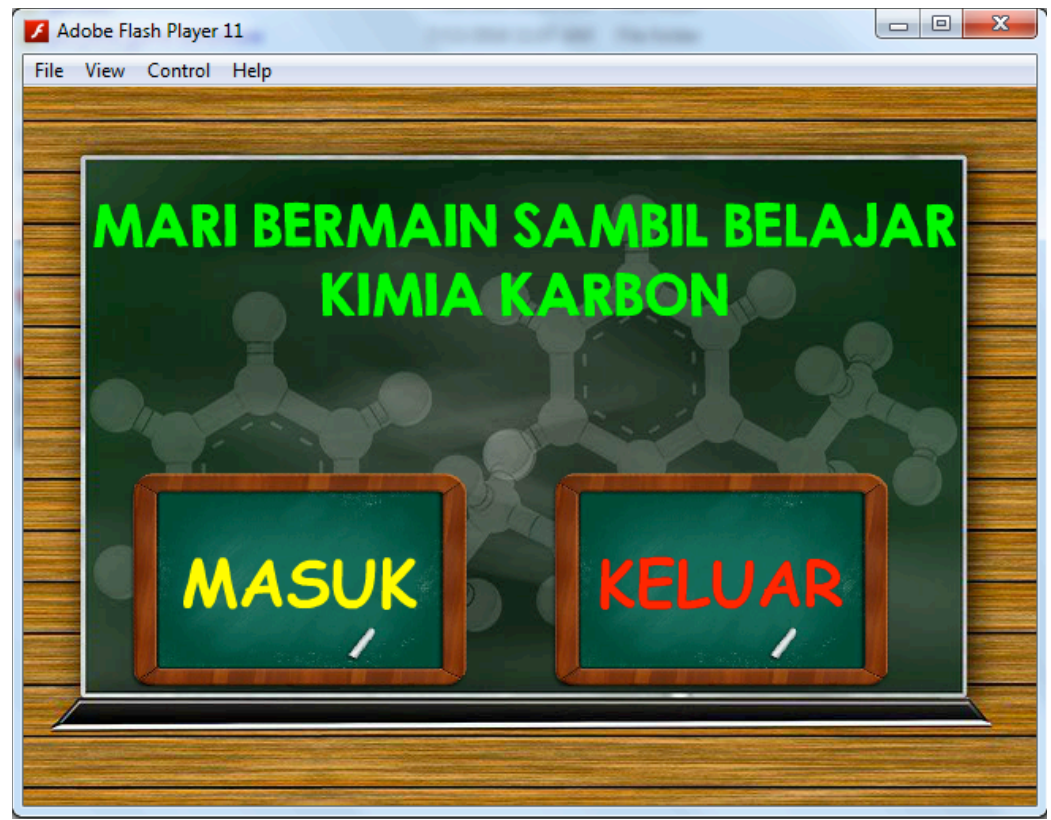

Gambar 6. Tampilan Halaman Pembuka

Halaman menu permainan merupakan halaman setelah pemain menekan button mari bermain pada halaman menu utama. Pada halaman menu permainan terdapat enam buah pilihan menu permainan berupa image button yaitu button hidrokarbon, button 
haloalkana, button turunan air, button karbonil, button karboksilat dan button keluar. Pada halaman ini sama dengan halaman menu utama menggunakan teknik motion tween dan setiap button disisipkan sound effect yang bila di tekan sound akan terdengar.

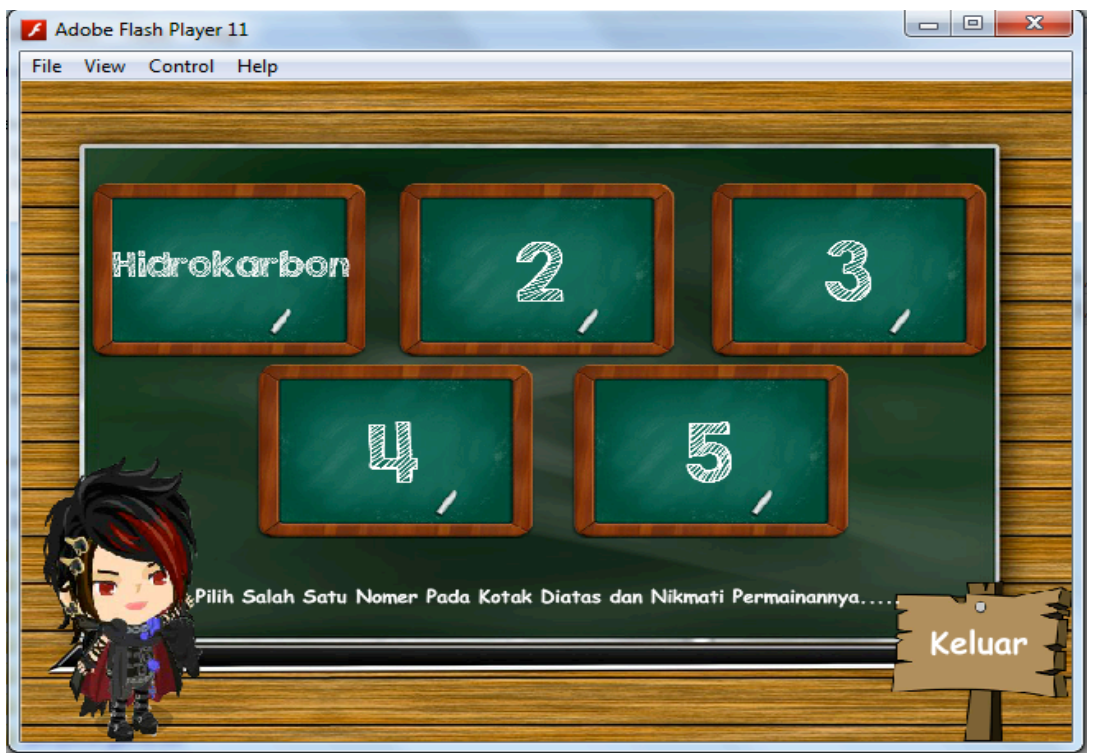

Gambar 7. Tampilan Halaman Menu Permainan

Pada permainan ini akan menampilkan sebuah soal tatanama salah satu unsur yang masuk golongan hidrokarbon seperti alkana,alkena dan alkuna. Permainan ini menggunakan teknik Drag and Drop dimana setelah soal muncul akan tampil rantai struktur yang masih kosong yang di bawahnya terdapat icon unsur yang harus di dicocokan ke dalam kotak yang membentuk rantai untuk membentuk suatu rumus struktur yang utuh.
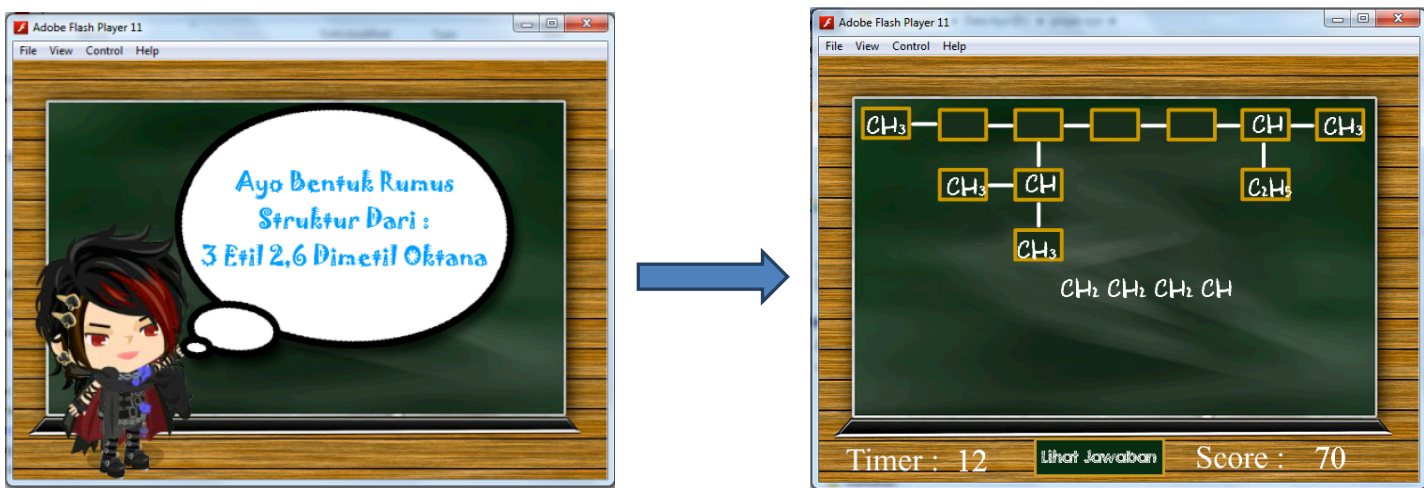

Gambar 8. Tampilan Permainan

Tahap berikutnya adalah uji coba sistem aplikasi ini dengan cara dijalankan pada Flash Movie, dengan uji coba ini dapat diketahui kekurangan atau kelemahan dari aplikasi ini, seperti menu tidak berjalan, tombol tidak berfungsi dan sebagainya. Dalam uji coba aplikasi ini terdapat beberapa tahap yang akan dilakukan, yaitu
a. Uji Coba Struktural
b. Uji Coba Fungsional
c. Uji Coba Validasi 


\section{KESIMPULAN}

Kesimpulan dari pembuatan aplikasi Model Pembelajaran Kimia Karbon Berbasis Game menggunakan software Adobe Flash CS 6 dengan bahasa pemrograman ActionScript 3.0. Dalam aplikasi di muat permainan menyusun rumus struktur kimia karbon dengan menggunakan teknik multimedia yaitu Drag and Drop. Aplikasi juga menyediakan pembahasan singkat mengenai kimia karbon berikut contoh dari masing-masing rumus struktur dari setiap tata nama yang ada dalam kimia karbon.

Setelah melakukan uji coba pada respondent siswa maka diraih hasil sebagai berikut : Effect : 87,5 \%, Control : 100\%, Efficiency : 100\%, Helpfulness : 80\%, Learnability : $90 \%$. Sedangkan pada respondent ahli diraih hasil sebagi berikut : Effect : 92,5\%, Control : 100\%, Efficiency : 100\%, Helpfulness : 80\%, Learnability : 90\%. Dari hasil tersebut menunjukan bahwa pembuatan model pembelajaran ini dianggap dapat membantu siswa dalam mempelajari kimia karbon selain menggunakan media buku karena memiliki kesesuaian materi dengan materi yang di ajarkan. Model Pembelajaran Kimia Karbon ini diharapkan dapat di kembangkan menjadi sebuah game edukasi berbasis Android, dengan menambahkan materi mengenai jenis reaksi yang ada pada senyawa karbon.

\section{DAFTAR PUSTAKA}

[1] Basri, Yulia I,2011. Pemanfaatan Animasi Multimedia Pada Mata Kuliah Kimia Teknik Untuk Peningkatan Pemahaman Mahasiswa Terhadap Konsep Ikatan Kimia. Jurnal Teknologi Informasi Vo.4 Tahun 2011

[2] Boyle, T. 1997. Design for Multimedia Learning. CEC Faculty Article

[3] Darsono. 2001. Belajar dan Pembelajaran. Semarang : IKIP Semarang Press

[4] Drag and Drop. http://blog.flashindonesia.com/2010/02/drag-dan-drop-di-flash. 12 November 2016

[5] Hamalik. 1994. Media Pendidikan. Bandung : Citra Aditya Bakti

[6] Kozma, Robert. 2008. Multimedia Learning of Chemistry. Cambridge Handbook of Multimedia Learning.

[7] Lorna Curran. 1994. Metode Pembelajaran Make a Match. Jakarta: Pustaka Belaja

[8] Nurani, Bezael, 2014. Perancangan dan Implementasi Aplikasi Multimedia pada Tabel Periodik Unsur Kimia Menggunakan HTML5. Artikel Ilmiah Program Studi Informatika Universitas Kristen Satya Wacana Salatiga

[9] Suprayekti. 2003. Interaksi Belajar Mengajar. Jakarta. Direktorat Tenaga Kependidikan, Dikdasmen, Depdiknas. 